\title{
Mechanistic studies on the reactivity of sensitizing allylic hydroperoxides: investigation on the covalent modification of amino acids by carbon-radical intermediates
}

\author{
Dany Kao, ${ }^{\mathrm{a}}$ Alain Chaintreau, ${ }^{\mathrm{b}}$ Jean-Pierre Lepoittevin ${ }^{\mathrm{a}}$ and Elena Giménez- \\ Arnau*a $^{* a}$
}

\begin{abstract}
Many fragrance terpenes autoxidize yielding allylic hydroperoxides that are strong skin allergens. These chemicals are supposed to bind through radical reactions to proteins in the skin to start the immunotoxic process characterizing skin sensitization, and further allergic contact dermatitis. In order to get more insight into this reactivity, we investigated the chemical behavior of the allylic hydroperoxides responsible for the allergenicity of autoxidized limonene and linalool. We studied by liquid chromatography-mass spectrometry the reactivity in $\mathrm{Fe}(\mathrm{II}) / \mathrm{Fe}$ (III) systems, able to degrade peroxides in vivo, toward amino acids prone to radical reactions, together with glutathione. We validated that carbon radicals issued from these compounds alter directly the lateral chain of some of the amino acids tested forming adducts via radical processes. Though, in parallel, due to the high oxidative strength of the media, we show that redox processes can also be induced and engender chemical modifications on the amino acids themselves. Amino acids chemically modified by the oxidant stress can then react with radicals issued from the hydroperoxides through what we call a "non-direct" reactivity process. Understanding protein binding processes to allergenic allylic hydroperoxides needs thus to consider both, covalent binding of carbon radicals to the amino acids, and additional oxido-reduction processes contributing to their sensitizing potential.
\end{abstract}

\section{Introduction}

Allergic contact dermatitis is an important occupational and environmental health issue. It is a delayed-type hypersensitivity reaction induced by skin contacts with xenobiotic substances, and is the most frequent expression of immunotoxicity in humans. $^{1,2}$ Chemical allergens are unable themselves to stimulate an adaptive immune response. Immunogenicity is attained by formation of stable protein conjugates that will be recognized and processed for further presentation to the immune system. Most contact allergens contain the chemical function necessary to react with skin proteins and this way allow the formation of the immunogenic-antigenic complex. ${ }^{3}$ Though, there are also other allergens that are non-sensitizers originally, non-protein reactive, that become reactive species through metabolic activation in the skin, known as prohaptens, or under simple oxidation, for prehaptens. ${ }^{4}$ These chemicals account for at least one third of known allergens today.

Terpenes are widespread fragrance compounds of natural origin, used in the production of fine perfumes, fragranced cosmetics, household and industrial products. Some of them behave as prehaptens, as they autoxidize easily to form clear allergenic allylic hydroperoxides. This is the case for $R-(+)-$ limonene $\mathbf{1}$ and for linalool $\mathbf{2}$, forming $\mathbf{3}$ and $\mathbf{4}$ respectively (Scheme 1). ${ }^{5,6}$
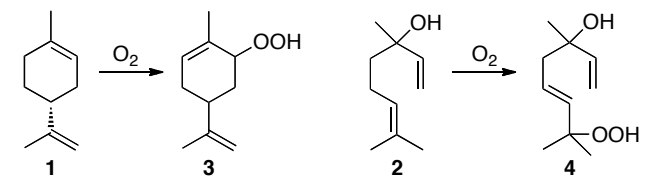

Scheme 1 Chemical structures of $R$-(+)-limonene 1 , linalool 2, 2hydroperoxylimonene $\mathbf{3}$ and 7-hydroperoxy-3,7-dimethylocta-1,5-dien-3-ol $\mathbf{4}$.

We know that, to be immunogenic, these hydroperoxides must react with proteins in the skin most probably via mechanisms involving radical intermediates. ${ }^{7}$ Cleavage of the hydroperoxide $\mathrm{O}-\mathrm{O} / \mathrm{O}-\mathrm{H}$ bonds, having bond dissociation energies that are relatively weak (175 and $\left.368 \mathrm{~kJ} \mathrm{~mol}^{-1}\right){ }^{8}$ affords alkoxyl RO• and peroxyl $\mathrm{ROO} \cdot$ radicals, which rapidly can lead to the formation of carbon-centered radicals $\mathrm{R} \bullet$ via intramolecular cyclization, fragmentation or hydrogen abstraction. ${ }^{9}$ Carbon-radical reactive intermediates derived from these xenobiotics could thus have an important role in damaging biomolecules. Supporting this hypothesis, clinical studies on allergenic hydroperoxides of different chemical structures show that allergic responses are specific. This indicates that specific antigens formed from particular radicals derived from each hydroperoxide must be responsible for the allergenic activity. ${ }^{10}$

We have reported previously the identification and possible involvement in allergic contact dermatitis of carbon-centered radicals $\mathrm{R} \cdot$ derived from allylic hydroperoxides using chemical traps. ${ }^{9,11,12}$ Recently, we examined the formation of carbon $\mathrm{R} \cdot$ intermediates derived from $\mathbf{3}$ and $\mathbf{4}$ by using spin-trapping-EPR spectroscopy. ${ }^{13,14}$ Radical initiation by using $\mathrm{Fe}(\mathrm{II}) / \mathrm{Fe}(\mathrm{III})$ confirmed the formation of oxygenated $\mathrm{RO} \bullet / \mathrm{ROO} \bullet$ and carbon- 
centered $\mathrm{R} \cdot$ free radicals derived from these hydroperoxides. To first approach the reactivity of these species with amino acids, we demonstrated, using liquid chromatography combined to mass spectrometry (LC/MS), the formation of adducts via radical mechanisms between $\mathrm{R} \cdot$ derived from the hydroperoxides and $N$-acetyl-histidine methyl ester. ${ }^{13}$ To complement these studies, and based on knowledge we have acquired on radical formation from the spin-trapping-EPR spectroscopy analyses, we now report potential additional terpene-amino acid adducts obtained by reaction of $\mathbf{3}$ and $\mathbf{4}$ with several amino acids prone to radical reactions, together with reactivity toward glutathione (GSH). A Fe(II) or Fe(III) source was used as initiator of the radical reactions because of the known role in the degradation of peroxides in vivo. ${ }^{15}$ Reactivity was followed by liquid chromatography electrospray ionization tandem mass spectrometry (LC-ESI-MS/MS). Studies reported here give additional information on basic chemical mechanisms that could explain the reactivity of allylic hydroperoxides toward proteins and thus their sensitizing potential. The long-term effect of this research shall be further exact elucidation of the different potentially immunogenic protein chemical modifications.

\section{Experimental section}

Caution: Skin contact with allylic hydroperoxides must be avoided because they are skin-sensitizing substances.

\section{Chemicals}

Compounds 3 and 4 were synthesized using procedures we have reported previously. ${ }^{13} \mathrm{~N}$-Acetyl-cysteine methyl ester $(\mathrm{N}-$ Ac-Cys-OMe), $N$-acetyl-tyrosine ethyl ester ( $N$-Ac-Tyr-OEt), $N$-acetyl-tryptophan ethyl ester ( $N$-Ac-Trp-OEt), and GSH were purchased from Sigma-Aldrich (France) and $N$-acetyl-lysine methyl ester ( $N$-Ac-Lys-OMe) from Bachem (Germany). The amine and carboxyl groups of the amino acids were protected to mimic the structure as part of a protein sequence, and to avoid the reactivity of the amine terminus with hydroperoxide decomposition products having carbonyl groups (Schiff base formation). Each amino acid specific side-chain was thus available for reaction. All other reagents and solvents were obtained from commercial sources and used as received. Spectrophotometric grade acetonitrile (99.8\%) was used, and aqueous solutions were prepared with deionized water. Reactions were conducted in flame-dried glassware, under inert atmosphere of argon, and with previously deaerated solvents.

\section{Instrumentation}

LC-ESI-MS/MS analyses were performed using an ion trap mass Bruker HCT Ultra spectrometer or an Agilent QToF spectrometer. Both instruments were connected to an Agilent 1200SL-RRLC HPLC system. The HPLC system was equipped with a binary pump, an automatic sample injector and a diode array absorbance detector scanning 190 to $700 \mathrm{~nm}$. The samples were subjected to reverse phase chromatography on $\mathrm{C} 18$ columns (Thermo Hypersil Gold, $1 \times 100 \mathrm{~mm}, 1.9 \mu \mathrm{m}$ particle size; $1 \times 30 \mathrm{~mm}, 1.9 \mu \mathrm{m}$ particle size; Supelco Discovery, $2 \times$
$250 \mathrm{~mm}, 5 \mu \mathrm{m}$ particle size) at a flow rate of $0.2 \mathrm{~mL} / \mathrm{min}$. They were eluted from the column using a mobile phase A $(0.01 \%$ formic acid in $\mathrm{H}_{2} \mathrm{O}$ ) and a mobile phase $\mathrm{B}$ (acetonitrile) with a gradient. The gradient started at $2 \% \mathrm{~B}$ and was increased to $90 \%$ B after $20 \mathrm{~min}$, was at $90 \%$ B during $10 \mathrm{~min}$, and was decreased again to $2 \% \mathrm{~B}$ for the last $10 \mathrm{~min}$. After passing through the diode array absorbance detector, the eluent was directed to the connected ion trap mass spectrometer with a standard electrospray source. The ionization method used was ESI in the positive ion mode (heated capillary temperature $300^{\circ} \mathrm{C}$, gas flow $8 \mathrm{~L} / \mathrm{min}$, nebulizer gas $40 \mathrm{psi}$ ). Full scan mass spectra were acquired in the profile mode scanning $\mathrm{m} / \mathrm{z} 50$ to 1000. For the ESI-MS/MS studies, the mass spectrometer was equipped with the ESI source used for ESI-MS studies described above and with the same source parameter settings. The ionization mode was ESI in the positive ion mode. The isolation width was $4 \mathrm{~m} / \mathrm{z}$. Data were processed using Agilent MassHunter Qualitative Analysis software. Only molecular ions detected by LC-ESI-MS having an $\mathrm{m} / \mathrm{z}$ value in agreement with potential adducts were considered as molecular species provided that they were relatively abundant. Even if unlikely, the eventuality of these ions being fragments of other molecular species cannot be excluded. ${ }^{1} \mathrm{H}$ and ${ }^{13} \mathrm{C}$ NMR were recorded on a Bruker Avance 300 spectrometer $\left({ }^{1} \mathrm{H}, 300 \mathrm{MHz} ;{ }^{13} \mathrm{C}, 75\right.$ $\mathrm{MHz}$ ). Two-dimensional ${ }^{1} \mathrm{H}_{-}{ }^{13} \mathrm{C}$ NMR experiments HSQC (heteronuclear single-quantum correlation) and $\mathrm{HMBC}$ (heteronuclear multiple-bond correlation) were recorded on a Bruker Avance 400 spectrometer $\left({ }^{1} \mathrm{H}, 400 \mathrm{MHz} ;{ }^{13} \mathrm{C}, 100\right.$ $\mathrm{MHz}$ ). Chemical shifts ( $\delta)$ are reported in ppm and are referenced to TMS via the solvent signal $\left(\mathrm{CDCl}_{3}: \delta{ }^{1} \mathrm{H}=7.26, \delta\right.$ ${ }^{13} \mathrm{C}=77.0$ ).

\section{Reactivity studies: general procedure}

Hydroperoxide 3 (300 mg, $1.78 \mathrm{mmol})$ or 4 (140 mg, 0.76 $\mathrm{mmol})$ were dissolved in deareated $1: 1(\mathrm{v} / \mathrm{v}) \mathrm{H}_{2} \mathrm{O}$ /acetonitrile (100 $\mathrm{mL}$ for 3, $50 \mathrm{~mL}$ for 4). The amino acids or GSH (2 equiv) were added, together with a catalytic amount ( 0.1 equiv) of $\mathrm{FeCl}_{3}$ (Fe(III) source) or $\mathrm{FeSO}_{4}$ heptahydrate (Fe(II) source). The reaction mixtures were continuously stirred at room temperature, and kept under argon atmosphere to minimize competing reactions with oxygen. Reactions were monitored by TLC $\left(0.25 \mathrm{~mm}\right.$ silica gel plates; $\left.60 \mathrm{~F}_{254}\right)$. After migration, TLC plates were inspected under UV light $(254 \mathrm{~nm})$, then sprayed with a solution containing phosphomolybdic acid $(5 \mathrm{~g})$, cerium (IV) sulfate $(2 \mathrm{~g})$ and sulphuric acid $(12 \mathrm{~mL})$ in $\mathrm{H}_{2} \mathrm{O}(188 \mathrm{~mL})$, or a solution containing $p$-anisaldehyde $(0.5 \mathrm{~mL})$, $o$ anisaldehyde $(0.5 \mathrm{~mL})$, sulphuric acid $(5 \mathrm{~mL})$ and ethanol $(8$ $\mathrm{mL})$ in acetic acid $(100 \mathrm{~mL})$, followed by heating. Reactions were stopped after 7 days if the starting hydroperoxides were still present in the reaction mixtures and the reactions did not evolve after that time. The mixtures were filtered on Celite (Celite 545) in order to remove iron salts. The solvent was removed under reduced pressure. The crude products were analyzed by LC-ESI-MS associated with ESI-MS/MS. Only in the case of the reaction with $N$-Ac-Cys-OMe the crude product could be fractionated by column chromatography on silica gel 
(Geduran ${ }^{\circledR} 60,40-63 \mathrm{~mm}$ ), in order to try to elucidate its nature by NMR (Supplementary Information data).

\section{Results and discussion}

\section{Reactivity with $N$-Ac-Cys-OMe}

Cysteine is one of the most labile residues involved in radical reactions induced by peroxides. Gardner et al. proposed a radical mechanism for the reaction, catalyzed by $\mathrm{FeCl}_{3}$, of linoleic acid hydroperoxide with $N$-Ac-Cys. Reaction products resulted from a thio-bond formation between the thiyl radical derived from the side-chain of cysteine and a carbon-centered radical derived from the hydroperoxide. ${ }^{16,17}$ As in our studies, reactions were carried out in argon atmosphere to minimize the competing reaction with oxygen and assure higher formation of adducts. ${ }^{17,18}$ This was also described for the $\mathrm{Fe}(\mathrm{II}) / \mathrm{Fe}(\mathrm{III})$ mediated chemistry of artemisinin and synthetic 1,2,4-trioxanes with GSH. ${ }^{19}$

Allylic hydroperoxide 3 . Compound 3 was totally consumed within one hour when incubated with $\mathrm{N}$-Ac-Cys-OMe. When the reaction was initiated with $\mathrm{FeCl}_{3}$, LC-MS of the crude product showed one major peak with an associated $\mathrm{m} / \mathrm{z}$ of 353 corresponding to the cysteine disulfide dimer 5 (Fig. 1), and two other peaks with $\mathrm{m} / \mathrm{z} 328$ and 344. MS fragmentation of 328 showed a fragment ion at $\mathrm{m} / \mathrm{z} 178$ due to the loss of $\mathrm{N}$-AcCys-OMe. Mechanistically, cysteine is known to reduce Fe(III), and hydroperoxides to oxidize $\mathrm{Fe}(\mathrm{II})$. Under reduction of $\mathrm{Fe}(\mathrm{III})$ thiyl radicals are formed, and $\mathrm{Fe}(\mathrm{II})$ can then generate RO radicals through a Fenton-like reaction. As we have shown previously with a monocyclic hydroperoxide model, these RO• are able to perform allylic hydrogen abstraction. ${ }^{9}$ In the case herein, most labile protons are those in position $\alpha$ to the double bonds, as the carbon-centered radical so formed would have been stabilized by resonance. Hydrogen abstraction being thus possible from positions 4 and 5, structures $6 \mathbf{a}$ and $6 \mathbf{b}$ can be suggested (Fig. 1). The value of the $[\mathrm{M}+\mathrm{H}]^{+}$molecular ion at $\mathrm{m} / \mathrm{z} 344$ corresponds to a mass increment of 16 from $\mathrm{m} / \mathrm{z} 328$, and could thus match with hydroperoxide analogues $7 \mathbf{a} / 7 \mathbf{b}$.

Exceptionally in this single case, we could perform some NMR analysis. For all other reactions described in this manuscript, isolation of products in the very complex mixtures was no longer possible and NMR analysis could not be performed. Two fractions were isolated from the crude product by column chromatography on silica gel (acetone/pentane 1:9, acetone/pentane 2:8). One corresponded to the cysteine disulfide dimer 5. HSQC experiments showed two protons at $3.19 \mathrm{ppm}$ correlated to a carbon atom at $40.7 \mathrm{ppm}, \delta$ characteristic of the $-\mathrm{CH}_{2}$ in position $\alpha$ to the disulfide bond (Supplementary Information data). NMR analysis of the second fraction suggested the formation of two diasteromers. ${ }^{1} \mathrm{H}_{-}{ }^{13} \mathrm{C}$ NMR HSQC and HMBC data revealed that the vinyl group and the isoprenyl group of $\mathbf{3}$ had been preserved during the reaction. The experiments also suggested the replacement of the initial hydroperoxide methylallyl group of $\mathbf{3}$ by a secondary alcohol methylallyl function, confirming the preservation of the menthene ring. Finally, there was a cysteine unit linked as the characteristic $\delta$ of the $-\mathrm{CH}_{2}$ in position $\alpha$ to the thiol group of the side-chain at $27.2 \mathrm{ppm}$ shifted to $34.9 \mathrm{ppm}$ with protons at 2.96/3.10 ppm (Supplementary Information data). The NMR information was in agreement with adducts $\mathbf{6 a / 6 b}$ (Fig. 1), for which two diasteromers are possible. The ipso hydrogen atom to the hydroxyl group and the methyl groups being preserved, hydrogen abstraction could only be from positions 4 and 5 affording $6 \mathbf{a}$ and $\mathbf{6 b}$ respectively. However, NMR data did not help to discriminate between the two regioisomers $6 \mathbf{a}$ and $\mathbf{6 b}$, even if $\mathrm{NMR}{ }^{1} \mathrm{H}$ and ${ }^{13} \mathrm{C} \delta$ of the isoprenyl group should be slightly different depending on the sulfur atom fixing position. As we have described previously, ${ }^{9}$ a suggestion for the formation of $\mathbf{6 a}$, applicable also for $\mathbf{6 b}$, is given in Scheme $2 .{ }^{20}$
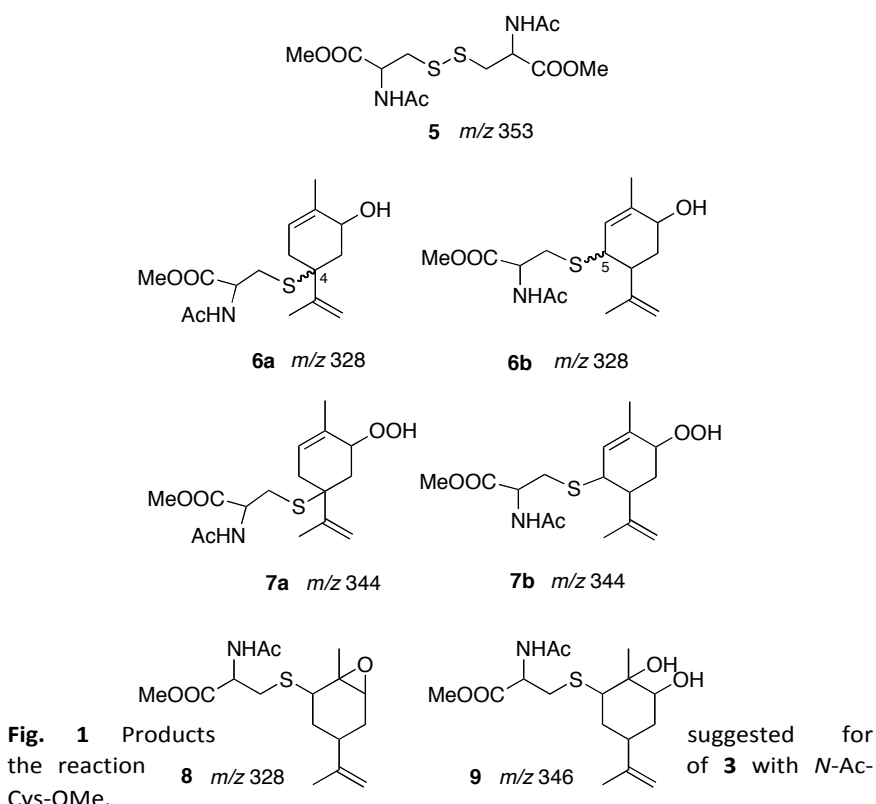
Cys-OMe.

In the reaction initiated with $\mathrm{FeSO}_{4}$, the LC-MS profile of the crude product was somewhat different (Fig. 2a). Disulfide dimer 5 was not the major species, and two significant peaks with $[\mathrm{M}+\mathrm{H}]^{+}$molecular ion at $m / z 328$ appeared at $t_{\mathrm{R}} 2.5$ and $2.7 \mathrm{~min}$. ESI-MS/MS of the peak at $t_{\mathrm{R}} 2.5 \mathrm{~min}$ was identical to the one obtained in the reaction with $\mathrm{FeCl}_{3}$ and was attributed to $\mathbf{6 a} / \mathbf{6 b}$. However, $m / z 328$ can also fit with epoxide 8 (Fig. 1), explaining this way the second peak at $2.7 \mathrm{~min}$.

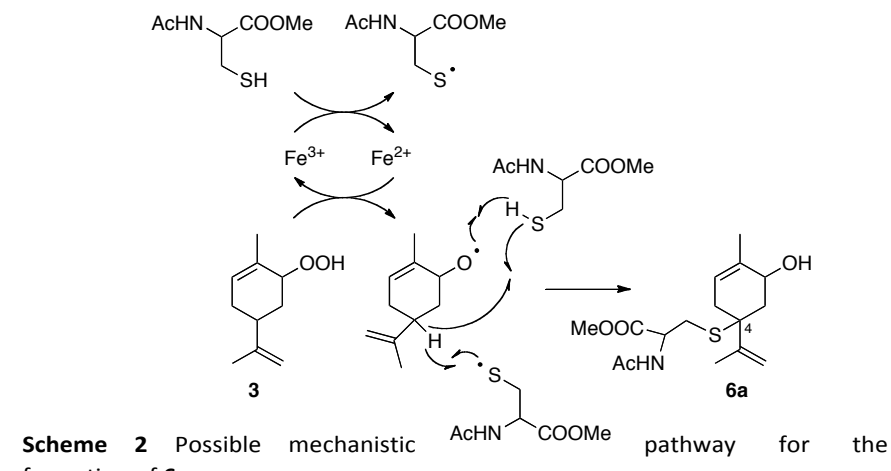

formation of $\mathbf{6 a}$. 


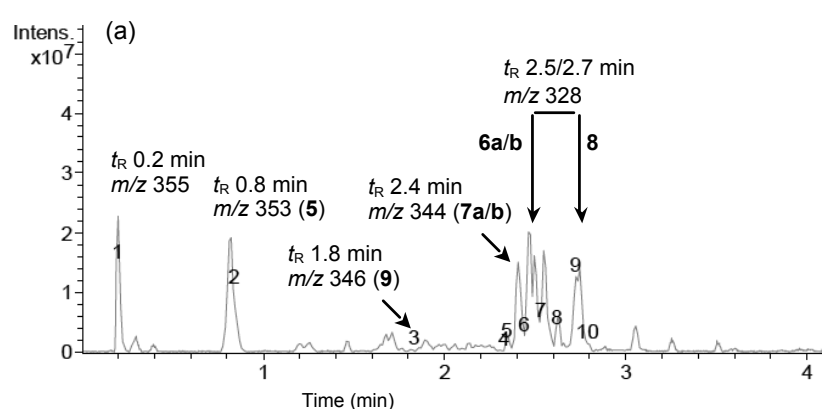

(b)

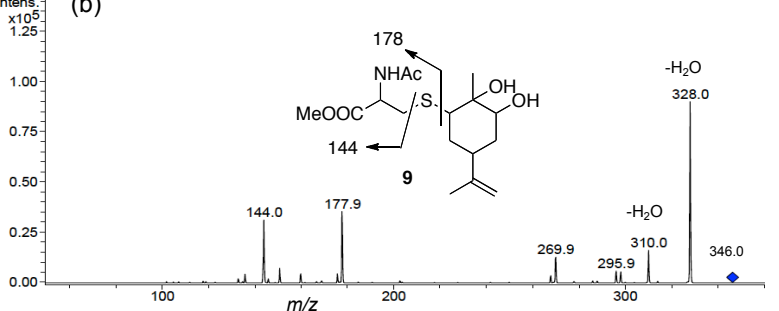

Fig. 2 Reaction 3/N-Ac-Cys-OMe/FeSO ${ }_{4}$ studied by LC-ESI-MS/MS. (a) LC chromatogram of the reaction. (b) ESI-MS/MS of $\mathrm{m} / z 346$ at $t_{\mathrm{R}} 1.8 \mathrm{~min}$.

ESI-MS/MS of the signal at $t_{\mathrm{R}} 2.7 \mathrm{~min}$ showed fragments at $\mathrm{m} / \mathrm{z}$ 178 and 144 typical from the loss of $N$-Ac-Cys-OMe. ${ }^{21}$ Mechanistically, the hydroperoxide is now able to oxidize $\mathrm{Fe}(\mathrm{II})$ to $\mathrm{Fe}$ (III) generating $\mathrm{RO} \bullet$ radicals. These, due to the presence of the allylic double bond, have been shown to undergo under these experimental conditions a fast cyclization to give $\alpha$-oxiranylcarbinyl radicals that can be trapped by the lateral chain of $\mathrm{N}$-Ac-Cys-OMe and afford $\mathbf{8}^{9,22}$ Indirect evidence of the formation of $\mathbf{8}$ was given by a tiny peak at $t_{\mathrm{R}}$ $1.8 \mathrm{~min}$ with a $\mathrm{m} / \mathrm{z}$ associated value of 346 . The mass increment of 18 with regard to $\mathrm{m} / \mathrm{z} 328$ corresponded to the addition of $\mathrm{H}_{2} \mathrm{O}$. ESI-MS/MS fragmentation was in agreement with compound 9 (Fig. 2b). It may then be suggested that nucleophilic addition of $\mathrm{H}_{2} \mathrm{O}$, present in the reaction solvent, on the electrophilic epoxide 8 afforded 9 . Adducts $7 \mathbf{a} / \mathbf{7 b}$ were identified at $t_{\mathrm{R}} 2.4 \mathrm{~min}$. Another molecular ion $(\mathrm{m} / \mathrm{z} 355)$ producing a $m / z 178$ fragment (loss of $N$-Ac-Cys-OMe) was identified but the structure could not be assigned.

Allylic hydroperoxide 4. Compound 4 needed few hours to react completely with $N$-Ac-Cys-OMe. Regardless of the experimental conditions used, prevailing oxidation of cysteine to form 5 was observed, together with a LC peak with $m / z 330$. On the other hand, only with Fe(II) compounds with $m / z 346$ and $m / z 364$ were detected. ESI-MS/MS of all the signals released the characteristic amino acid fragment at $\mathrm{m} / \mathrm{z} 144$ (Fig. 3 ). Based on the mechanisms discussed for the reactivity of hydroperoxide 3, structures 10 and 11 matched with $\mathrm{m} / \mathrm{z}$ 346, and 12 with $m / z$ 364. Unlike 3, allylic hydrogen abstraction is here possible at a single position, forming compound 10. The fact that 12 was observed only with $\mathrm{Fe}$ (II) was again in agreement with the favored formation of $\alpha$-oxiranylcarbinyl radicals in these experimental conditions, at the origin of compound 11. For the first time $\beta$-scission of initially obtained $\mathrm{RO} \cdot$ radicals could be suggested (Scheme 3), as $\mathrm{m} / \mathrm{z} 330$

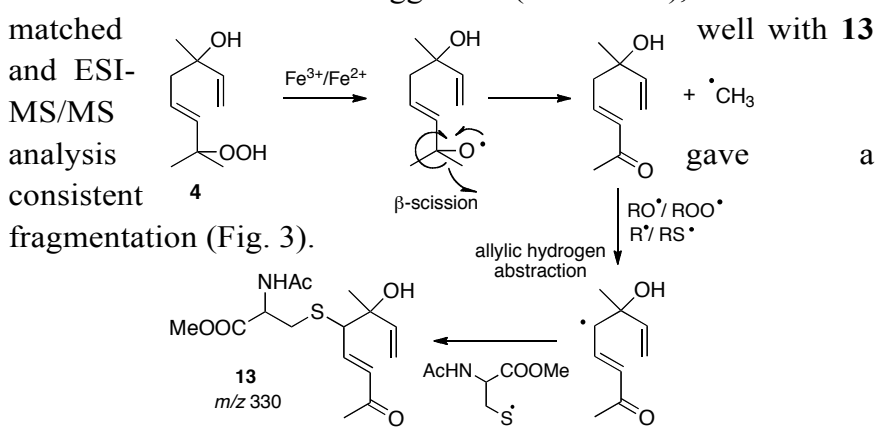

Scheme 3 Mechanistic pathway suggested for the formation of $\mathbf{1 3}$

Observations on the results. Reactivity studies of 3 with $\mathrm{N}$ Ac-Cys-OMe have been already reported in the literature. ${ }^{23}$ Our studies bring some more new information on this reactivity, complemented with that of hydroperoxide 4. Previously, the reactivity of 3 with $\mathrm{N}$-Ac-Cys-OMe in the presence of 5,10,15,20-tetraphenyl-21H,23H-porphyrin iron (III) chloride was studied by LC-MS. Adducts different from the ones we report here were described. ${ }^{23}$ The authors observed also LC-MS peaks with $\mathrm{m} / \mathrm{z} 328$ and 344 . They showed that $\mathbf{3}$ evolves easily to the formation of carvone in the presence of iron, ${ }^{14}$ and proved thus accurately the formation of adducts by addition of the thiol group of cysteine either to the endocyclic bond of carvone or to the double bond of its isoprenyl group through a 2-electron reaction pathway, adducts having $\mathrm{m} / \mathrm{z} 328$. In our studies, adducts with $\mathrm{m} / \mathrm{z} 328$ were in agreement with $\mathbf{6 a} / \mathbf{6 b}$ (Fig. 1), where the isoprenyl group had been preserved and the hydroperoxide methylallyl group replaced by a secondary alcohol methylallyl function (Supplementary Information data). Data agreed with the formation of a $\mathrm{RO} \cdot$ radical further performing allylic hydrogen abstraction. We showed this kind of reactivity in earlier studies using a monocyclic 15hydroperoxyabietic acide-like compound as model of allergenic hydroperoxide. ${ }^{9}$ We also suggest the formation of $\mathbf{8}$, converted into observed compound $9(\mathrm{~m} / \mathrm{z} 346)$ after opening of the epoxide function by attack of $\mathrm{H}_{2} \mathrm{O}$. The fact that we characterized these adducts does not exclude the addition of cysteine on carvone. The experimental conditions being different, all kind of adducts should be pondered. 

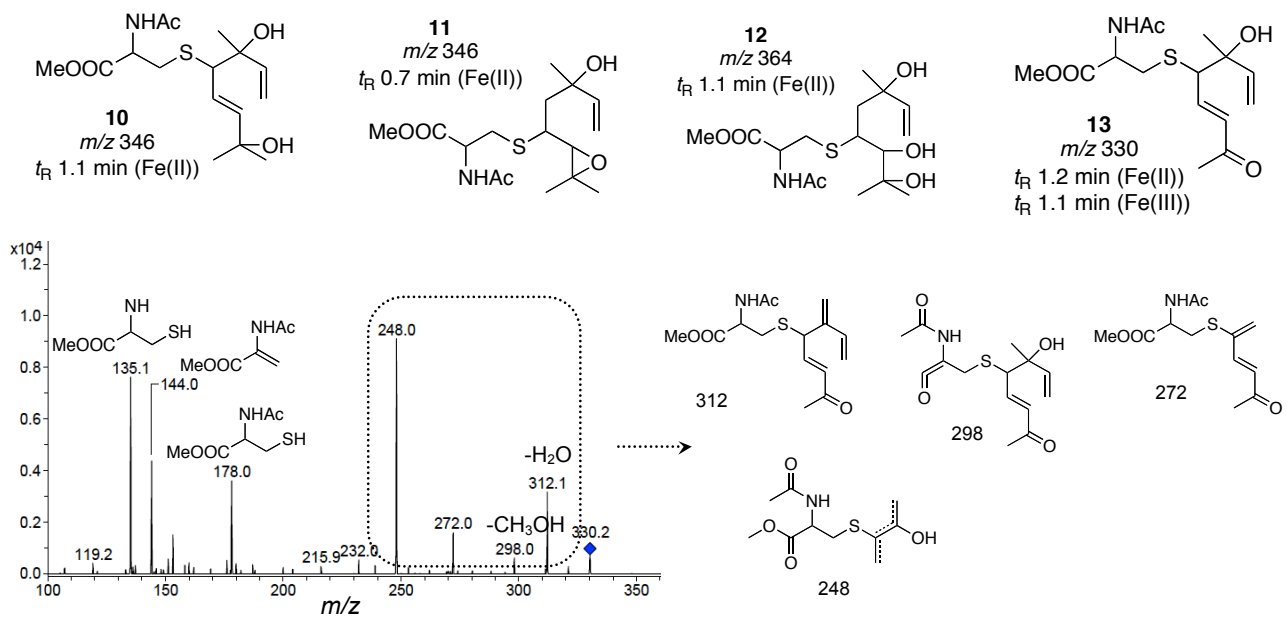

Fig. 3 Adducts 10-13 observed by LC-ESI-MS/MS from the reaction 4/N-Ac-Cys-OMe $\left(t_{R}\right.$ are indicated when using Fe(II) and Fe(III)) and ESI-MS/MS analysis of $m / z$ 330.

For $m / z$ 344, structures derived also from carvone were proposed, from addition of the thiol group to the endocyclic or to the double bond of the isoprenyl group with oxidation/epoxidation of either one double bond or the other $(\mathrm{m} / \mathrm{z}$ 344=N-Ac-Cys-OMe+carvone+O). It was considered that the increment of $m / z 16(+\mathrm{O})$ could not fit with an $\mathrm{OOH}$ group as all starting material was consumed. However, it is known that the mechanism for the $\mathrm{O}-\mathrm{O}$ bond cleavage of hydroperoxides by $\mathrm{Fe}(\mathrm{III})$ porphyrin complexes can induce the presence of $\mathrm{RO} \cdot$ and $\mathrm{ROO} \cdot$ radicals simultaneously in the reaction media. ${ }^{24,25}$ Even if there is no a clear agreement on the mechanism, Traylor et al. proposed a heterolytic O-O cleavage, followed by a fast side reaction between a so formed highvalent $\mathrm{Fe}(\mathrm{IV})$ oxo porphyrin cation radical intermediate and the hydroperoxide, resulting in the formation of both $\mathrm{RO} \cdot$ and ROO• radicals. ${ }^{26}$ Our previous EPR studies on the formation of radicals from $\mathbf{3}$ in iron systems confirmed indeed the coexistence of both kind of radicals in the solutions. ${ }^{13,14}$ Through a similar mechanism to that depicted in Scheme 2 for $\mathrm{RO} \cdot$ radicals, the so formed ROO• could form carbon radical species via abstraction of allylic hydrogen. In the present studies, this was confirmed by the potential obtention of $7 \mathbf{a} / 7 \mathbf{b}$ with $\mathrm{m} / z$ 344. Looking all in all at these results, it seems clear that distinct adducts can be formed due to the complex redox mechanisms involved in the reactions. It is thus possible that in our experiments small amounts of adducts described elsewhere had also been formed but could not be identified. The same kind of chemistry outlined for $\mathbf{3}$ was applicable to 4 . The formation of adducts through reaction of the thiol group resulted from allylic hydrogen abstraction, possible at one single position (adduct 10), and from the formation of $\alpha$ oxiranylcarbinyl radicals with further opening of the epoxide cycle (adducts 11, 12). Interestingly in the case of 4 , the acyclic chemical structure could allow $\beta$-scisssion of the $\mathrm{RO} \cdot$ radicals (adduct 13), this process being favoured with $\mathrm{Fe}(\mathrm{III})$.

\section{Reactivity with $N$-Ac-Trp-OEt}

Tryptophan is a redox-active amino acid playing a decisive role in a number of biological multistep electron transfer processes. Several studies have thus focused on the characterization of tryptophan radicals in proteins. ${ }^{27-30}$

Allylic hydroperoxide 3. Reactivity was far slower, as $\mathbf{3}$ was not completely consumed after a week. The crude product LCMS profile was identical with Fe(II) or Fe(III) (Fig. 4). Several oxidation/degradation products of $N$-Ac-Trp-OEt were identified. The indole functional group was susceptible to oxidation giving mono and dihydroxylated derivatives $\mathbf{1 4}$ and 15. Tryptophan oxidation by hydroxyl radicals in $\mathrm{Fe}(\mathrm{II}) / \mathrm{Fe}(\mathrm{III})$ redox systems is indeed known. ${ }^{31-33}$ 2-,4-,5-,6-, and 7-hydroxyltryptophan isomers have been reported. Monohydroxylated derivative $\mathbf{1 4}$ can thus correspond to many different position isomers. This could explain why several LC peaks had $\mathrm{m} / \mathrm{z}$ values of 291. The same argument is realistic for dihydroxylated derivatives 15. Like in our studies, dihydroxylation of tryptophan has been reported in the literature by the observation of an increment of $\mathrm{m} / \mathrm{z} 32$ to the amino acid mass. ${ }^{34}$ Oxidative degradation of $N$-Ac-Trp-OEt afforded also $N$-Ac- $N$ '-formylkynurenine-OEt 16 and $N$-Ackynurenine-OEt 17. This was not surprising as the kynurenine pathway accounts for the principal oxidative ring opening and subsequent degradation of tryptophan in mammalian cells. ${ }^{35} \mathrm{~A}$ peak with $m / z 441$ was observed, and ESI-MS/MS analysis showed a fragment with $\mathrm{m} / \mathrm{z} 275$ typical of $N$-Ac-Trp-OEt loss, this being characteristic of an 18-like adduct. 

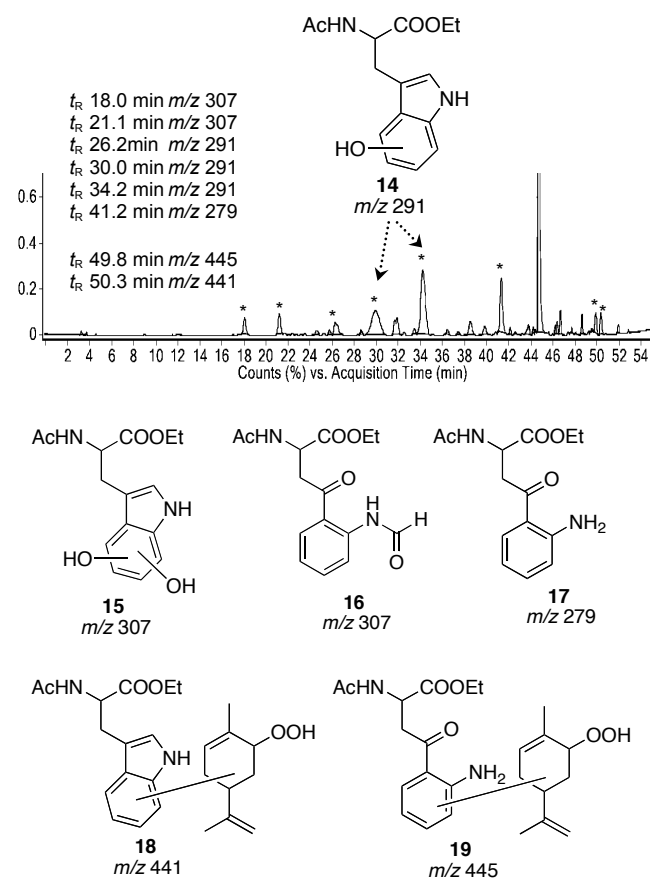

Fig. 4 Reaction $3 / \mathrm{N}$-Ac-Trp-OEt/ $/ \mathrm{FeCl}_{3}$ : LC chromatogram of the crude product, peaks with $\mathrm{m} / \mathrm{z}$ associated values of interest, and chemical structures of amino acid oxidation/degradation products 14-17 and adducts 18-19.

Also, a peak with $m / z 445$ was detected and ESI-MS/MS showed the loss of a fragment with $\mathrm{m} / \mathrm{z} 279$ specific to $N$-Ackynurenine-OEt 17. This was in agreement with a 19-like structure. Mechanistically, a carbon radical R・ issued from 3 could react with a carbon radical located on the aromatic lateral chain of $N$-Ac-Trp-OEt or $N$-Ac-kynurenine-OEt. Several positions are available for radical formation in the case of tryptophan as shown by the mentioned studies on its oxidation and hydroxylation. ${ }^{3.33}$ Thus, the binding of $\mathrm{R} \cdot$ could happen in different lateral chain positions of $N$-Ac-Trp-OEt preventing the exact elucidation of the chemical structure of 18. Regarding $\mathrm{N}$-Ac-kynurenine-OEt, the amino group would favour the addition of $\mathrm{R} \cdot$ in the $\alpha$ position. Yet, LC-ESI-MS/MS data did not allow drawing a conclusion concerning the exact chemical structure of 19.

Allylic hydroperoxide 4. As for 3, 4 remained still in the reaction mixture after a week. Oxidation products 14-17 were identified. Only in the presence of $\mathrm{Fe}(\mathrm{II}), \mathrm{m} / \mathrm{z}$ values of 443 and 459 were observed, corresponding to adducts. MS/MS of $\mathrm{m} / \mathrm{z}$ 443 matched with structures 20-21 (Fig. 5). A carbon R• issued from $\mathrm{RO} \cdot$ hydrogen abstraction could react with a carbon radical located on the aromatic lateral chain of $N$-Ac-Trp-OEt and afford 20. Also, the allylic RO radical could follow an intramolecular cyclization and the $\alpha$-oxiranylcarbinyl radical so formed react to give 21. There was a single loss of $\mathrm{H}_{2} \mathrm{O}$ but structure 20 was still favored, as epoxyalcohols and epoxides follow a different fragmentation pattern. ${ }^{36}$ Typical MS fragments of tryptophan ( $m / z 130$ and 157) were observed. ${ }^{37}$ The value $\mathrm{m} / \mathrm{z} 459$ corresponded to a mass increase of 16 from $m / z$ 443. MS/MS analysis gave a fragment derived from tryptophan with $m / z \quad 146$, thus a 16 mass increase from the typical $\mathrm{m} / \mathrm{z} 130$ tryptophan fragment (Fig. 5). Knowing that $\mathrm{N}$ Ac-Trp-OEt was oxidized in the reaction media to form 14-like mono-hydroxylated derivatives, we considered that these could further react with a carbon $\mathrm{R} \cdot$ derived from the hydroperoxide. Even if this could occur with an oxiranylcarbinyl radical or with a radical derived from hydrogen abstraction, affording adducts $\mathbf{2 2}$ and $\mathbf{2 3}$ respectively, the loss this time of 2 molecules of $\mathrm{H}_{2} \mathrm{O}$ was in favor of the formation of $\mathbf{2 2}$.

Observations on the results. Several reaction mechanisms seem to be involved. Adducts can be formed from radical processes between tryptophan itself and carbon radicals derived from the hydroperoxides, in what we call a "direct" reaction amino acid-hydroperoxide (adducts 18, 20 and 21). In parallel, oxido-reduction processes were induced by $\mathbf{3}$ and $\mathbf{4}$, producing chemical modifications on the amino acid. Modified tryptophan could then react with the allergen, through a "non-direct" reactivity process. The amino acid did not react directly, but an intermediate formed as a consequence of oxidant stress. Oxidation/degradation products of $N$-Ac-Trp-OEt were identified such as 14-17. Due to the oxidative strength of the reaction media containing hydroperoxides, this was not surprising as the kynurenine pathway and hydroxylation processes are known oxidative degradations of tryptophan. Up to our knowledge, this is the first time these reactive intermediates were observed in the presence of allergenic allylic hydroperoxides. Moreover, they were able to react, most probably through radical mechanisms, with the hydroperoxides. This was the case for 19, resulting from the reaction between $\mathrm{N}$ Ac-kynurenine-OEt $\mathbf{1 7}$ and 3, and for adducts 22-23, resulting from the reaction of monohydroxylated 14-like derivatives with carbon radicals derived from 4.

\section{Reactivity with $N$-Ac-Lys-OMe}

It has been reported in the literature the formation of an amidelike adduct between 13-hydroperoxyoctadecadienoic acid and $\mathrm{N}$-benzoyl-glycyl-lysine, used as model for lysine residues in proteins. Also, lysine oxidation has been extensively reported giving rise, among others, to hydroxylated derivatives or fragments possessing highly reactive carbonyl groups. ${ }^{38-41}$

Allylic hydroperoxide 3. The reaction was slow. After a week, 3 was not completely consumed. The LC-MS profile of the crude product was identical with $\mathrm{Fe}(\mathrm{II})$ or $\mathrm{Fe}(\mathrm{III})$ initiation. Oxidation of $N$-Ac-Lys-OMe was not observed. Only one possible adduct was detected with $\mathrm{m} / z 353$ (Fig. 6). The presence of the lysine residue was attested by MS/MS, giving a fragment typical for the loss of $N$-Ac-Lys-OMe $(\mathrm{m} / \mathrm{z} 203)$, together with fragments $m / z 171$ and 129 , principal ions derived from fragmentation of the amino acid itself. ${ }^{42,43}$ Curiously, the production of amides by $\mathrm{Cu}(\mathrm{II})$ catalyzed reaction between 13hydroperoxyoctadecadienoic acid and primary amines has been reported. $^{44}$ 


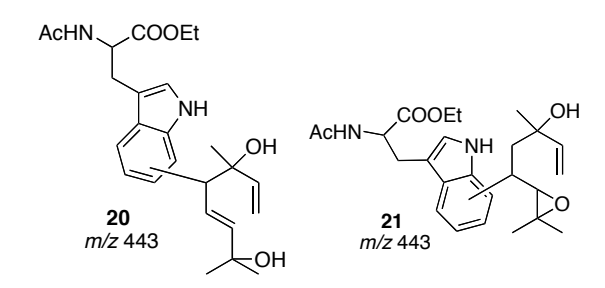

x10 4 + Product Ion (9.795-9.903 min, 2 scans) $(443.00000[z=1]$ - >
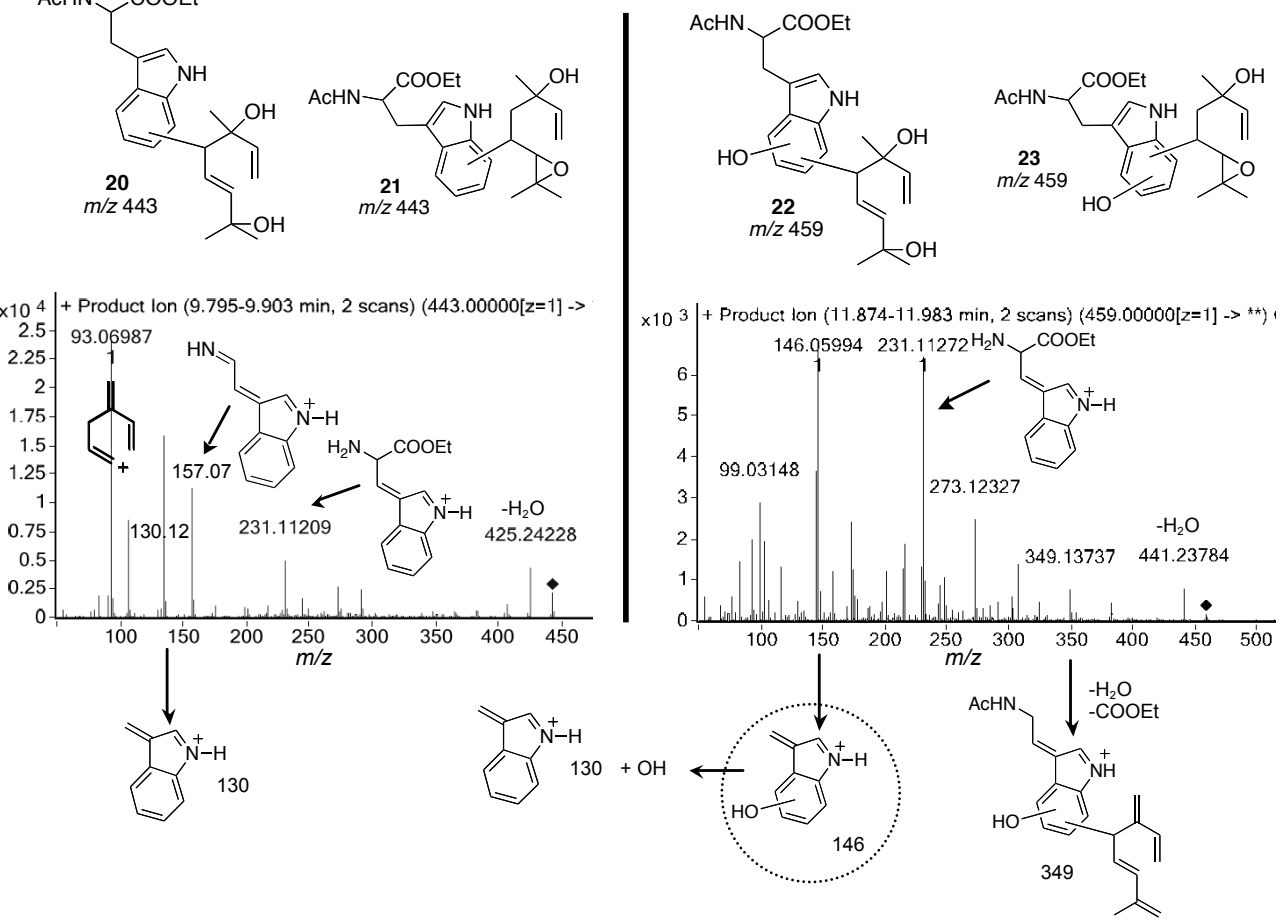

3 + Product Ion (11.874-11.983 min, 2 scans) (459.00000[z=1] >**)

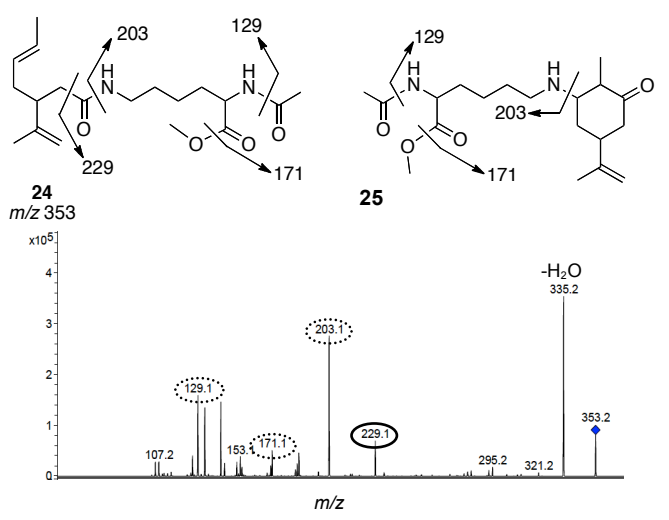

Fig. 6 Reaction 3/N-Ac-Lys-OMe/FeSO ${ }_{4}$. ESI-MS/MS of $\mathrm{m} / \mathrm{z} 353$ and proposed structures 24 and 25.

It was proposed that a carbonyl intermediate formed from metal catalyzed reduction of the hydroperoxide was involved in the reaction. The reaction continued by the formation of a carbinolamine adduct by addition of the amine on the carbonyl intermediate, followed by a metal-catalyzed oxidative cleavage of the carbon-carbon bond adjacent to the carbonyl group. Based on a similar mechanism, it would be possible to suggest the formation of adduct $\mathbf{2 4}$ via the formation of carvone from metal catalyzed reduction of $\mathbf{3}$ (Scheme 4). Another possible structure could be ketone 25, obtained through a 1,4-Michael addition reaction of the amino group of lysine on carvone. MS/MS of $m / z 353$ gave characteristic fragments of the amino acid, these being the same for $\mathbf{2 4}$ and $\mathbf{2 5}$. Though, the presence of a distinguishing fragment at $\mathrm{m} / \mathrm{z} 229$ would be more in favor of the formation of 24. Indeed, fragment with $\mathrm{m} / \mathrm{z} 229$, containing the $\varepsilon-\mathrm{NH}_{2}$ group of lysine modified by the addition of a carbonyl group, would not be formed from adduct 25 .

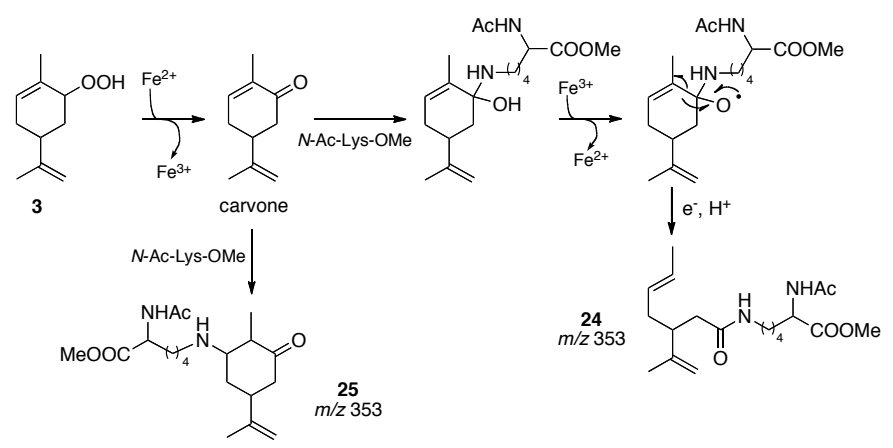

Scheme $\mathbf{4}$ Mechanism proposed for the formation of $\mathbf{2 4}$ and $\mathbf{2 5}$.

Allylic hydroperoxide 4. After a week, 4 was not completely consumed. LC-MS of the crude product showed the formation of peaks with molecular ions at $\mathrm{m} / z 339$ and $\mathrm{m} / \mathrm{z} 357$. MS/MS of $m / z 339$ gave a $m / z 186$ known fragment derived from the loss of $\mathrm{N}$-Ac-Lys-OMe free amino group (Scheme 5). ${ }^{42}$ Data were in agreement with the structure suggested for $\mathbf{2 6}$. As observed in the reaction with cysteine, $\beta$-scission of RO• radicals could happen, and reaction between the $\alpha, \beta$ unsaturated ketone formed, at the carbonyl level, and the amino group of lysine could afford Schiff base 26. The free amino group of lysine could also add through a 1,4-Michael addition to the $\alpha, \beta$-unsaturated ketone and form 27 , which has the $\mathrm{m} / \mathrm{z}$ value of 357 . MS/MS of $\mathrm{m} / \mathrm{z} 357$ afforded fragment at $\mathrm{m} / \mathrm{z} 271$ 
which chemical structure was in full agreement with the hypothetical formation of 27.

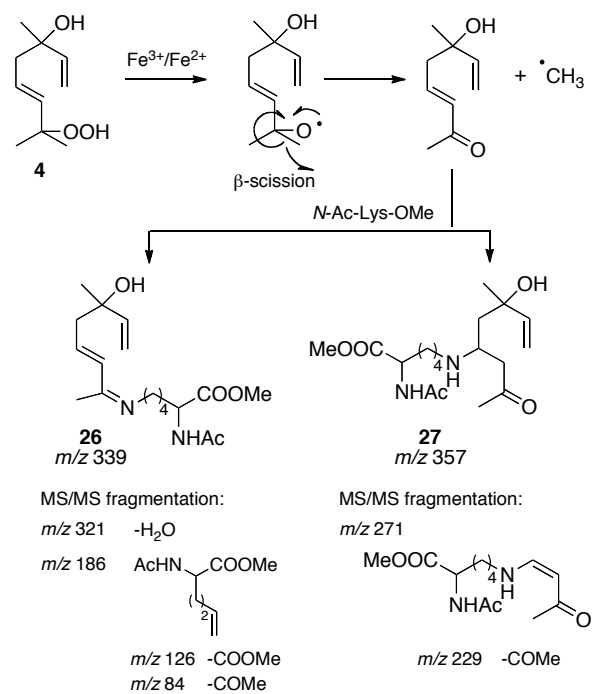

Scheme 5 Reaction 4/N-Ac-Lys-OMe/FeSO 4 . Structures proposed for $m / z 339$ and 357 and MS/MS fragmentation results.

Observations on the results. As mentioned above, the evolution of 3 to the formation of carvone in the presence of iron is known. ${ }^{14,23}$ The previously reported participation of carvone in the reaction $\mathbf{3}$ /cysteine was in our case highlighted when studying the reactivity with $N$-Ac-Lys-OMe. The formation of 24-25 could be mechanistically explained by the reaction of the amino group of lysine with carvone, itself obtained by decomposition of the hydroperoxide, either by 1,4Michael addition, either by the formation of a carbinolamine adduct, followed by a metal-catalyzed oxidative cleavage of the carbon-carbon bond adjacent to the carbonyl group. These results are in agreement with the fact that carvone is a determinant reactive intermediate for hydroperoxide 3 . On another hand, $\beta$-scission of $\mathrm{RO}$ - radicals formed from linalool hydroperoxide 4 , already seen in the reactivity with cysteine, was supported in here by results obtained from the reactivity with $\mathrm{N}$-Ac-Lys-OMe. The free amino group of lysine could react through a 2-electron reaction pathway with the $\alpha, \beta$ unsaturated ketone so formed, either at the carbonyl level giving 26, either through a 1,4-Michael addition forming 27.

\section{Reactivity with $N$-Ac-Tyr-OEt}

Tyrosine chemical modification by biologically relevant oxidants typically depends on the formation of tyrosyl radicals located in carbon-centered positions on the benzene ring. EPR evidence of electron-transfer mechanisms in the peroxynitritemediated oxidation of tyrosine has been reported. ${ }^{45}$ Moreover, for proteins associated with hydrophobic environments, it has been reported that lipid peroxyl radicals can mediate tyrosine oxidation processes. ${ }^{46}$
Allylic hydroperoxide 3. LC chromatograms showed, regardless of $\mathrm{Fe}(\mathrm{II}) / \mathrm{Fe}(\mathrm{III})$, a major peak corresponding to $\mathrm{N}$ Ac-Tyr-OEt $(\mathrm{m} / \mathrm{z} 252)$, together with two weak distinct peaks with $\mathrm{m} / \mathrm{z}$ value of 501 (Supplementary Information data). These could correspond to dityrosine $\mathbf{2 8}$ and to the Pummerer-like ketone 29, both known oxidation products of tyrosine (Scheme 6). ${ }^{45,47}$ In presence of $\mathrm{Fe}(\mathrm{III})$ a possible adduct with $\mathrm{m} / \mathrm{z} 418$ was observed but in a very tiny amount, not excluding thus that it could be formed with $\mathrm{Fe}$ (II) in an undetectable amount. As expected, MS/MS of $m / z 418$ afforded the characteristic $N$-AcTyr-OEt fragment $(\mathrm{m} / \mathrm{z} 252)$, suggesting a 30-like adduct (Supplementary Information data). Unfortunately, no further data could be obtained in order to give more detailed information on the chemical structure.

Allylic hydroperoxide 4. In all experiments, only amino acid oxidation products $\mathbf{2 8}$ and $\mathbf{2 9}$ were detected.

Observations on the results. $\mathrm{RO} \bullet / \mathrm{ROO} \bullet$ and carbon-centered free radicals derived from $\mathbf{3}$ and $\mathbf{4}$ could mediate, as for lipid peroxyl radicals, ${ }^{46}$ the formation of phenoxy tyrosine radicals. Further radical isomerization involves the formation of monomers that can, by diradical reaction, combine between themselves affording 28 and 29 (Scheme 6). The chemical modification of tyrosine due to the relevant oxidant properties of allylic hydroperoxides was thus confirmed by the formation of large amounts of tyrosine-tyrosine dimers 28-29.

\section{Reactivity with GSH}

GSH plays a major role protecting cells against oxidative stress and free radical damage, directly neutralizing free radicals and reactive oxygen species. ${ }^{48,49}$ Its biological activity is due to the potent electron-donating capacity of the thiol group, able to scavenge highly reactive radicals that damage cells through oxidative stress. Hence, because the oxidant nature of $\mathbf{3}$ and $\mathbf{4}$, we studied the reactivity toward GSH.

Allylic hydroperoxide 3. 3 was fully consumed after one hour of reaction. Oxidized form GSSG was not observed. LC-MS of the crude product exhibited molecular ions at $\mathrm{m} / \mathrm{z} 458$ and 476 . Similar to the reactivity with cysteine, $\mathrm{m} / \mathrm{z} 458$ was initially attributed to compound $\mathbf{3 1}$ but could also match with compound 32 (Fig. 7a). The ability of GSH to reduce iron efficiently is well known. ${ }^{50}$ Thus, a similar mechanism to the one described in Scheme 2 can be suggested for the formation of 31-like adducts, being the major drawback the impossibility to know exactly the position of GSH binding. On another hand, cyclization of allyloxyl RO radicals afford $\alpha$-oxiranylcarbinyl radicals that can be trapped by GSH to form 32. 31-32 structures cannot be assigned unambiguously. Indirect evidence of 32 was given by the presence of the molecular ion at $\mathrm{m} / \mathrm{z}$ 476. ESI-MS/MS indicating the loss of two molecules of $\mathrm{H}_{2} \mathrm{O}$ together with GSH was in agreement with 33 (Fig. 7a). The mass increment of 18 with regard to $m / z 458$ would correspond to the addition of $\mathrm{H}_{2} \mathrm{O}$ on epoxide 32 . 


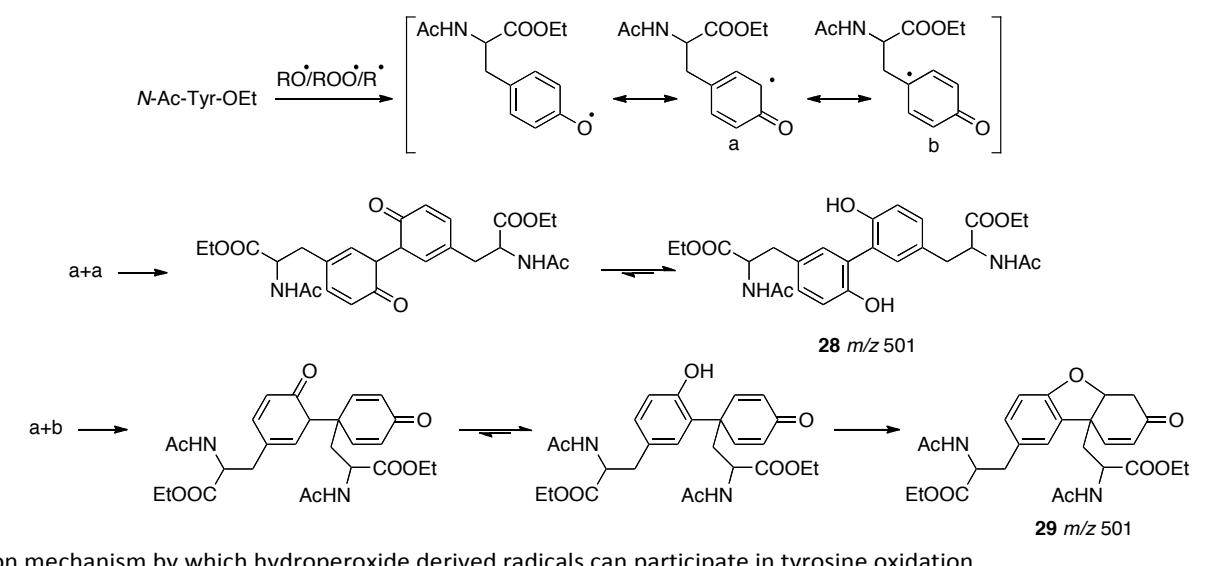

Scheme 6 Proposed reaction mechanism by which hydroperoxide derived radicals can participate in tyrosine oxidation.

Allylic hydroperoxide 4. 4 needed few hours to completely react in all experimental conditions. GSSG was not observed. The most attracting signals are shown in Fig. 7b-7c. Fragmentation of $\mathrm{m} / \mathrm{z} 462$ showed the typical peak [GSH+H] ${ }^{+}$ at $m / z 308$, together with peaks of characteristic fragmentation of GSH conjugates. ${ }^{51,52} \mathrm{~m} / \mathrm{z} 462$ corresponded well with 34. As for the reaction with cysteine, $\beta$-scission of $\mathrm{RO} \cdot$ radicals to form an $\alpha, \beta$-unsaturated ketone could be possible. While in that case there was radical addition of the amino acid on the carbon radical formed during the $\beta$-scission process and after allylic hydrogen abstraction, this time $\mathrm{m} / \mathrm{z} 462$ was in favour of a 1,4Michael addition of the -SH group of GSH on the $\alpha, \beta$ unsaturated ketone. By analogy with the observed reactivity for 3, structures 35 and 36 could match with $m / z$ 476, and 37 with $\mathrm{m} / \mathrm{z}$ 494. Unlike $\mathbf{3}$, allylic hydrogen abstraction was only possible at one position forming 35. Again, indirect evidence of the possible formation of epoxide $\mathbf{3 6}$ was the existence of the signal with a mass increment of 18 , at $\mathrm{m} / \mathrm{z} 494$, corresponding to 37 and resulting from the epoxide opening by $\mathrm{H}_{2} \mathrm{O}$.

(a)

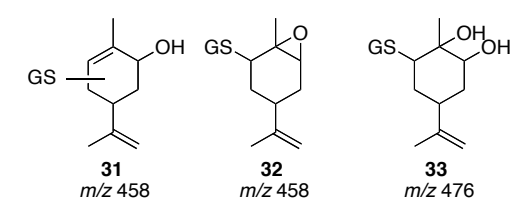

(c)

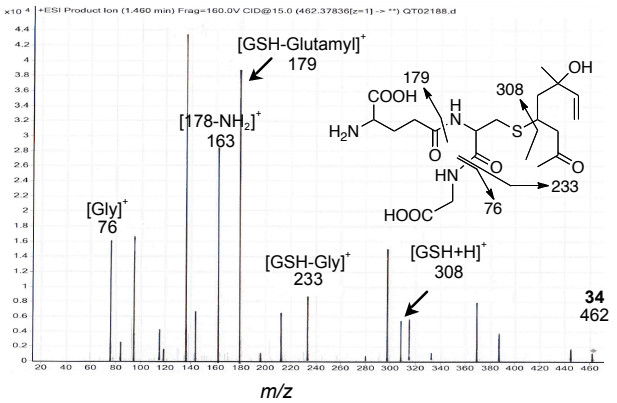

Observations on the results. Reactivity of 3 with GSH was in agreement with results found for the reactivity with cysteine. This can be resumed to the formation of $\mathrm{RO}$, and further allylic hydrogen abstraction or intramolecular cyclization to form carbon radicals reacting with the $-\mathrm{SH}$ group of GSH. As for cysteine, some authors studied previously the reactivity of $\mathbf{3}$ toward GSH. ${ }^{23}$ They gave arguments similar to those rationalized for the reactivity observed with cysteine. Adducts carvone-GSH $(\mathrm{m} / \mathrm{z} 458)$ and carvone $+\mathrm{GSH}+\mathrm{O}(\mathrm{m} / \mathrm{z} 474)$ were described. Thus, once more, the obtention of distinct adducts depending on the experimental conditions tested may be considered. The same kind of chemistry outlined for $\mathbf{3}$ was applicable to the reactivity of $\mathbf{4}$ with GSH. The formation of adducts through the reaction of the thiol group resulted from allylic hydrogen abstraction, only possible at one position in the case of $\mathbf{4}$, and from the formation of $\alpha$-oxiranylcarbinyl radicals with further opening of the epoxide cycle. The acyclic chemical structure of $\mathbf{4}$ allowed $\beta$-scisssion of the formed RO radical, and thus the formation of an electrophilic reactive intermediate that could form 34 through a 1,4-Michael addition.

(b)
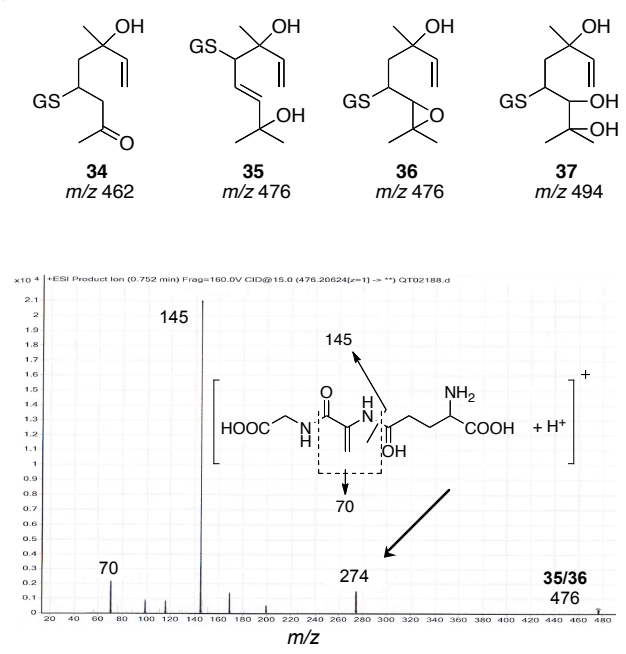


\section{Conclusions}

To complement previous studies on the identification of reactive radical intermediates issued from allergenic allylic hydroperoxides, we studied the potential reactivity of 2hydroperoxylimonene $\mathbf{3}$ and 7-hydroperoxy-3,7-dimethylocta1,5-dien-3-ol 4, derived from autoxidation of limonene and linalool, towards amino acids prone to radical reactions in order to give new insights on their supposed ability to form immunogenic structures by reacting with skin proteins through radical mechanisms. Studies reported here give innovative understanding on basic radical mechanisms that could explain the reactivity of allylic hydroperoxides towards proteins and thus their sensitizing potential. Radical initiation by using $\mathrm{Fe}(\mathrm{II}) / \mathrm{Fe}(\mathrm{III})$ redox cycles confirmed that carbon-centered radical intermediates derived from $\mathbf{3}$ and $\mathbf{4}$ can chemically modify amino acids by forming stable covalent bonds. It is known that reductive cleavage of peroxides and hydroperoxides occurs with reduced metals such as $\mathrm{Fe}(\mathrm{II})$, but also with cytochrome enzymes and related Fe(III)-heme-containig models. Indeed, reaction time and product outcome did not vary significantly depending on the starting ion used, Fe(II) or Fe(III). We have shown that the high oxidative strength of the media containing hydroperoxides induces the production of a number of reactive radical species involved in a permanent game of redox reactions. These intermediates are able to react with amino acids, either through a "direct" pathway with the lateral chain, either through a "non-direct" pathway with previous redox modification of the amino acid. The results of the reactivity with tryptophan are the perfect example underlining that the understanding of the hapten-protein binding process to allylic hydroperoxides needs to consider both, the direct binding to the amino acids via radical mechanisms, as well as the involvement of oxido-reduction processes able to produce chemical modifications on the amino acid itself. Amino acids chemically modified by the oxidant stress can then react with carbon-centered radicals issued from the hydroperoxides. Thus, a certain number of radical intermediates can issue from these compounds and be at the origin of different potentially immunogenic protein chemical modifications. These qualitative studies, even if elucidation of the exact chemical structure of the adducts is difficult, open new insights into the comprehension of mechanisms inducing chemical modification of biomolecules by carbon-centered radical species issued from xenobiotics.

\section{Acknowledgements}

We gratefully acknowledge Firmenich SA (Geneva, Switzerland) for financial support to D. K. We also thank Patrick Wehrung (Pharmaceutical Department, University of Strasbourg, France) for his valuable technical support on the LC-ESI-MS/MS studies.

\section{Notes}

${ }^{a}$ Laboratoire de Dermatochimie, Institut de Chimie de Strasbourg (CNRS UMR 7177), Université de Strasbourg, 4 Rue Blaise Pascal, 67081 Strasbourg, France.E-mail: egimenez@unistra.fr
${ }^{b}$ Firmenich SA, Corporate R\&D Division, 1 Route des Jeunes, 1211 Geneva 8, Switzerland

\section{References}

1 I. Kimber, D. A. Basketter, G. F. Gerberick and R. J. Dearman, Allergic contact dermatitis, Int. Immunopharmacol., 2002, 2, 201211.

2 T. Rustemeyer, I. M. W. van Hoogstraten, B. M .E. von Blomberg, S. Gibbs and R. J. Scheper, Mechanisms of irritant and allergic contact dermatitis, in Contact Dermatitis, $5^{\text {th }}$ edn., ed. J. D Johansen, P. J. Frosch and J. -P. Lepoittevin, Springer-Verlag, Berlin, Heidelberg, 2011, pp 43-90.

3 J. -P. Lepoittevin, Molecular aspects in allergic and irritant contact dermatitis, in Contact Dermatitis, $5^{\text {th }}$ edn., ed. J. D Johansen, P. J. Frosch and J. -P. Lepoittevin, Springer-Verlag, Berlin, Heidelberg, 2011, pp 91-110.

4 J. -P. Lepoittevin, Metabolism versus chemical transformation or proversus prehaptens?, Contact Dermatitis 2006, 54, 73-74.

5 A. -T. Karlberg, L. P. Shao, U. Nilsson, E. Gafvert and J. L. Nilsson, Hydroperoxides in oxidized d-limonene identified as potent contact allergens, Arch. Dermatol. Res., 1994, 286, 97-103.

6 M. Skold, A. Börje, E. Harambasic and A. -T. Karlberg, Contact allergens formed on air exposure of linalool. Identification and quantification of primary and secondary oxidation products and the effect on skin sensitization, Chem. Res. Toxicol., 2004, 17, 16971705 .

7 A. -T. Karlberg, M. A. Bergström, A. Börje, K. Luthman and J. L. G. Nilsson, Allergic contact dermatitis-Formation, structural requirements, and reactivity of skin sensitizers, Chem. Res. Toxicol., 2008, 21, 53-69.

8 Y. -R. Luo, BDEs of O-X bonds, in Comprehensive Handbook of Chemical Bond Energies, Taylor \& Francis Group, Boca Raton, 2007, pp 255-368.

9 E. Giménez-Arnau, L. Haberkorn, L. Grossi and J. -P. Lepoittevin, Identification of radical species derived from allergenic 15hydroperoxyabietic acid and insights into the behavior of cyclic tertiary allylic hydroperoxides in $\mathrm{Fe}(\mathrm{II}) / \mathrm{Fe}(\mathrm{III})$ systems, Tetrahedron, 2008, 64, 5680-5691.

10 J. Brared-Christensson, M. Matura, C. Backtorp, A. Börje, J. L. G. Nilsson and A. -T. Karlberg, Hydroperoxides form specific antigens in contact allergy, Contact Dermatitis, 2006, 55, 230-237.

11 M., Bezard, E. Giménez-Arnau, B. Meurer, L. Grossi and J. -P. Lepoittevin, Identification of carbon-centred radicals derived from linalyl hydroperoxide, a strong skin sensitizer: a possible route for protein modifications, Bioorg. Med. Chem., 2005, 13, 3977-3986.

12 E. Giménez-Arnau, L. Haberkorn, L. Grossi and J. -P. Lepoittevin, Identification of alkyl radicals derived from an allergenic cyclic tertiary allylic hydroperoxide by combined use of radical trapping and ESR studies, Tetrahedron, 2002, 58, 5535-5545.

13 D. Kao, A. Chaintreau, J. -P. Lepoittevin and E. Giménez-Arnau, Synthesis of allylic hydroperoxides and EPR spin-trapping studies on the formation of radicals in iron systems as potential initiators of the sensitizing pathway, J. Org. Chem., 2011, 76, 6188-6200.

14 S. Johansson, E. Giménez-Arnau, M. Grotli, A. -T. Karlberg and A. Börje, Carbon- and oxygen- centered radicals are equally important haptens of allylic hydroperoxides in allergic contact dermatitis, Chem. Res. Toxicol., 2008, 21, 1536-1547.

15 A. M. Szpilman, E. E. Korshin, R. Hoos, G. H. Posner and M. D. Bachi, Iron(II)-induced degradation of antimalarial $\beta$-sulfonyl endoperoxides. Evidence for the generation of potentially cytotoxic carbocations, J. Org. Chem., 2001, 66, 6531-6540. 
16 H. W. Gardner, D. Weisleder and R. Kleiman, Addition of $\mathrm{N}$ acetylcysteine to linoleic acid hydroperoxide, Lipids, 1976, 11, 127-134.

17 H. W. Gardner, R. D. Plattner and D. Weisleder, The epoxyallylic radical from homolysis and rearrangement of methyl linoleate hydroperoxide combines with the thiyl radical of $N$-acetylcysteine, Biochim. Biophys. Acta, 1985, 834, 65-74.

18 H. W. Gardner and P. A. Jursinic, Degradation of linoleic acid hydroperoxides by a cysteine. $\mathrm{FeCl}_{3}$ catalyst as a model for similar biochemical reactions. I. Study of oxygen requirement, catalyst and effect of pH, Biochim. Biophys. Acta, 1981, 665, 100-112.

19 C. Singh, N. Gupta and P. Tiwari, Chemistry of 1,2,4-trioxanes relevant to their mechanism of action. Part 1: Reaction with Fe(II) salts, Tetrahedron Lett., 2005, 46, 4551-4554.

20 L. Lunazzi, G. Placucci and L. Grossi, Temperature-controlled addition vs. abstraction by methylthiyl radical with cyclopentente, J. Chem. Soc., Chem. Commun., 1979, 533-534.

21 X. Perfetti, B. O’Mathuna, N. Pizarro, E. Cuyas, O. Khymenets, B. Almeida, M. Pellegrini, S. Pichini, S. S. Lau, T. J. Monks, M. Farré, J. A. Pascual, J. Joglar and R. de la Torre, Neurotoxic thioether adducts of 3,4-methylenedioxymethamphetamine identified in human urine after ectasy ingestion, Drug Metab. Dispos., 2009, 37, 1448-1455.

22 L. Grossi, S. Strazzari, B. C. Gilbert and A. C. Whitwood, Oxiranylcarbinyl radicals from allyloxyl radical cyclization: characterization and kinetic information via ESR spectroscopy, J. Org. Chem., 1998, 63, 8366-8372.

23 S.Johansson, T. Redeby, T. M. Altamore, U. Nilsson and A. Börje, Mechanistic proposal for the formation of specific immunogenic complexes via a radical pathway: a key step in allergic contact dermatitis to olefinic hydroperoxides, Chem. Res. Toxicol., 2009, 22, 1774-1781.

24 R. Labeque and L. J. Marnett, Homolytic and heterolytic scission of organic hydroperoxides by (meso-tetraphenylporphinato) iron(III) and its relation to olefin epoxidation, J. Am. Chem. Soc., 1989, 111, 6621-6627.

25 T. G. Traylor, C. Kim, W. -P. Fann and C. L. Perrin, Reactions of hydroperoxides with iron(III) porphyrins: heterolytic cleavage followed by hydroperoxide oxidation, Tetrahedron, 1998, 54, 7977-7986.

26 T. G. Traylor, S. Tsuchiya, Y. -S. Byun and C. Kim, High-yield epoxidations with hydrogen peroxide and tert-butyl hydroperoxide catalyzed by iron(III) porphyrins: heterolytic cleavage of hydroperoxides, J. Am. Chem. Soc., 1993, 115, 2775-2781.

27 J. Stubbe and W. A. Van der Donk, Protein radicals in enzyme catalysis, Chem. Rev., 1998, 98, 705-762.

28 S. Stoll, H. S. Shafaat, J. Krzystek, A. Ozarowski, M. J. Tauber, J. E. Kim and R. D. Britt, Hydrogen bonding of tryptophan radicals revealed by EPR at $700 \mathrm{GHz}$, J. Am. Chem. Soc., 2011, 133, 18098-18101.

29 H. S. Shafaat, B. S. Leigh, M. J. Tauber and J. E. Kim, Spectroscopic comparison of photogenerated tryptophan radicals in azurin: effects of local environment and structure, J. Am. Chem. Soc., 2010, 132, 90309039.

30 J. P. Eiserich, J. Butler, A. Van der Vliet, C. E. Cross and B.Halliwell, Nitric oxide rapidly scavenges tyrosine and tryptophan radicals, Biochem. J., 1995, 310, 745-749.

31 Z. Maskos, J. D. Rush and W. H. Koppenol, The hydroxylation of tryptophan, Arch. Biochem. Biophys., 1992, 296, 514-520.

32 E. L. Finley, J. Dillon, R. K, Crouch and K. L. Schey, Identification of tryptophan oxidation products in bovine $\alpha$-crystallin, Protein $S c i, 1998$, 7, 2391-2397.

33 T. J. Simat and H. Steinhart, Oxidation of free tryptophan and tryptophan residues in peptides and proteins, J. Agr. Food Chem., 1998, 46, 490498.

34 D. -Q. Peng, Z. Wu, G. Brubaker, L. Zheng, M. Settle, E. Gross, M. Kinter, S. L. Hazen and J. D. Smith, Tyrosine modification is not required for myeloperoxidase-induced loss of apolipoprotein A-I functional activities, J Biol Chem., 2005, 280, 33775-33784.
35 R. Schwarcz, The kynurenine pathway of tryptophan degradation as a drug target, Curr. Opin. Pharmacol., 2004, 4, 12-17.

36 T. Nilsson, I. V. Ivanov and E. H. Oliw, LC-MS/MS analysis of epoxyalcohols and epoxides of arachidonic acid and their oxygenation by recombinant CYP4F8 and CYP4F22, Arch. Biochem. Biophys., 2010, 494, 64-71.

37 M. R. M. Domingues, P. Domingues, A. Reis, C. Fonseca, F. M. L. Amado and A. J. V. Ferrer-Correia, Identification of oxidation products and free radicals of tryptophan by mass spectrometry, J. Am. Soc. Mass Spectrom., 2003, 14, 406-416.

38 B. Morin, W. A. Bubb, M. J. Davies, R. T. Dean and S. Fu, 3Hydroxylysine, a potential marker for studying radical induced protein oxidation, Chem. Res. Toxicol., 1998, 11, 1265-1273.

39 E. R. Stadtman and R. L. Levine, Free radical-mediated oxidation of free amino acids and amino acid residues in proteins, Amino Acids, 2003, 25, 207-218.

40 C. L Hawkins and M. J. Davies, Generation and propagation of radical reactions on proteins, Biochim. Biophys. Acta, 2001, 1504, 196-219.

41 Y. Kato, Y. Mori, Y. Makino, Y. Morimitsu, S. Hiroi, T. Ishikawa and T.Osawa, Formation of $N \varepsilon$-(hexanonyl)lysine in protein exposed to lipid hydroperoxide, J. Biol. Chem., 1999, 274, 20406-20414.

42 T. Yalcin and A. G. Harrison, Ion chemistry of protonated lysine derivatives, J. Mass Spectrom., 1996, 31, 1237-1243.

43 F. Fenaille, J. -C. Tabet and P. A. Guy, Study of peptides containing modified lysine residues by tandem mass spectrometry: precursor ion scanning of hexanal-modified peptide, Rapid Commun. Mass Spectrom., 2004, 18, 67-76.

44 J. M. Onorato, A. J. Jenkins, S. R. Thorpe and J. W. Baynes, Pyridoxamine, an inhibitor of advanced glycation reactions, also inhibits advanced lipoxidation reactions, J. Biol. Chem., 2000, 275, $21177-$ 21184.

45 L. Grossi, Evidence of an electron-transfer mechanism in the peroxynitrite-mediated oxidation of 4-alkylphenols and tyrosine, J. Org. Chem., 2003, 68, 6349-6353.

46 S. Bartesaghi, J. Wenzel, M. Trujillo, M. Lopez, J. Joseph, B. Kalyanaraman and R. Radi, Lipid peroxyl radicals mediate tyrosine dimerization and nitration in membranes, Chem. Res. Toxicol., 2010, 23, 821-835.

47 C. Giulivi, N. J. Traaseth and K. J. A. Davies, Tyrosine oxidation products: analysis and biological relevance, Amino Acids, 2003, 25, 227-232.

48 P. M. Kidd, Glutathione: systemic protectant against oxidative and free radical damage, Alt. Med. Rev., 1997, 2, 155-176.

49 M. Valko, D. Leibfritz, J. Moncol, M. T. D. Cronin, M. Mazur and J. Telser, Free radicals and antioxidants in normal physiological functions and human disease, Int. J. Biochem. Cell Biol., 2007, 39, 44-84.

50 M. Tien, J. R. Bucher and S. D. Aust, Thiol-dependent lipid peroxidation, Biochem. Biophys. Res. Commun., 1982, 107, 279-285.

51 C. M. Murphy, C. Fenselau and P. L. Gutierrez, Fragmentation characteristic of glutathione conjugates activated by high-energy collisions, J. Am. Soc. Mass Spectrom., 1992, 3, 815-822.

52 E. Camera, M. Rinaldi, S. Briganti, M. Picardo and S. Fanali, Simultaneous determination of reduced and oxidized glutathione in peripheral blood mononuclear cells by liquid chromatographyelectrospray mass spectrometry, J. Chromatogr. B., 2001, 757, 69-78. 